NOTICE: This is the author's version of a work that was accepted for publication in the International Journal of Human-Computer Studies. Changes resulting from the publishing process, such as peer review, editing, corrections, structural formatting, and other quality control mechanisms, may not be reflected in this document.

Changes may have been made to this work since it was submitted for publication. A definitive version was subsequently published in the International Journal of Human-Computer Studies, Volume 87, March 2016, DOI:

http://dx.doi.org/10.1016/j.ijhcs.2015.11.004

Please cite as:

Burigat S., Chittaro L., Passive and Active Navigation of Virtual Environments vs. Traditional Printed Evacuation Maps: a

Comparative Evaluation in the Aviation Domain, International Journal of Human-Computer Studies, 87, March 2016, pp. 92-105.

\title{
Passive and Active Navigation of Virtual Environments vs. Traditional Printed Evacuation Maps: a Comparative Evaluation in the Aviation Domain
}

\author{
Stefano Burigat ${ }^{\mathrm{a}, *}$, Luca Chittaro $^{\mathrm{a}}$ \\ ${ }^{a}$ HCI Lab, Dept. of Mathematics and Computer Science, University of Udine, \\ Via delle Scienze 206, 33100, Udine, Italy
}

\begin{abstract}
Printed maps are the most common tool to prepare people for emergency evacuation in contexts such as public buildings or transportation. Unfortunately, they are poorly understood and often ignored by people. Virtual environments (VEs) could be a more effective method to support people in acquiring spatial knowledge about the real-world environment to evacuate. This paper pursues three main goals. First, we propose a VE-based tool to support spatial knowledge acquisition for evacuation purposes, using aviation as a real-world domain in which such knowledge is crucial for passengers safety. Second, we study in detail one of the VE design choices (active or passive navigation), comparing a version of our tool in which users navigate by actively controlling their position with another version in which users are passively led along pre-defined routes. Third, we contrast the two versions of the tool with the traditional, printed diagrammatic map provided to passengers by airlines. Results of our study show that the VE-based approach produces objectively better spatial knowledge when users are asked to pinpoint their assigned position in the environment, and that active navigation produces a performance improvement in a subsequent virtual evacuation. Moreover, the VE-based approach is perceived as more enjoyable, easier to comprehend and more effective than printed maps when active navigation is available.
\end{abstract}

Keywords: Virtual environments, navigation, maps, evacuation, safety, education, training, aviation

\section{Introduction}

During emergency evacuations, previously acquired spatial knowledge of the environment plays a crucial role in reducing risks to occupant's safety. Unfortunately, the printed evacuation maps that typically provide emergency-related spatial knowledge in buildings (e.g., hotels, schools, companies) and in transportation (e.g., aircraft, trains, ships) are very limited. Such maps provide only an abstract diagrammatic representation that: (i) can present comprehension problems, (ii) needs cognitively complex geometric operations to translate the knowledge provided by the map into actual routes in the environment, (iii) is difficult to mentally match with the

${ }^{*}$ Corresponding author

Email addresses: stefano. burigat@uniud.it (Stefano Burigat), luca. chittaro@uniud.it (Luca Chittaro) Preprint submitted to Elsevier

January 18, 2016 
real-world environment, especially in case of emergency evacuation, which requires fast actions and decisions to maximize probability of survival, (iv) does not allow users to preview what they are going to see from their real-world egocentric view when following an evacuation route.

Compared to printed evacuation maps, virtual environments (VEs) in the form of desktop 3D interactive simulations of real-world environments might offer a more useful tool to prepare people for emergency evacuations. Indeed, there is significant evidence that VEs can be used to help people acquire spatial knowledge about real-world places and navigate those places more efficiently and effectively (Arthur et al., 1997; Foreman et al., 2000; Klatzky et al., 1998; Richardson et al., 1999; Ruddle et al., 1997; Waller et al., 1998; Wilson et al., 1997b; Witmer et al., 1996).

The purpose of our project is to leverage the power of VEs to create novel tools for emergency evacuation preparedness and to evaluate on users if such tools are actually more effective than the printed maps currently in use. In particular, we focus on aviation as a real-world domain in which fast and efficient evacuation is fundamental to increase passengers' chances of avoiding harm. In a previous paper (Chittaro and Buttussi, 2015), we proposed a VE-based serious game aimed at educating passengers about safety procedures (e.g., brace position, usage of the life vest) in the case of an emergency water landing and evacuation scenario. In this paper, we propose a VEbased tool that combines a VE representation of the cabin with an electronic map of an aircraft to support spatial knowledge acquisition for evacuation purposes. We study in detail one of the VE design features (active and passive navigation), highlighting the effects on users' knowledge and behavior of a version of the tool in which users navigate by actively controlling their position and a version in which users are passively led along pre-defined routes. Moreover, we contrast the two versions of the tool with the currently employed solution, i.e., the printed diagrammatic maps (safety cards) provided to passengers by airlines.

Our work advances the state of the art in spatial knowledge acquisition through VEs in several directions:

- We try a VE-based approach to provide emergency-related spatial knowledge in a domain (aviation safety) in which it has never been studied before.

- We investigate if a combination of VEs and electronic maps provides advantages over a paper map in terms of spatial knowledge acquisition, a question that received inconsistent answers in the literature.

- We contribute to the body of knowledge on active and passive navigation, studying the effectiveness of the two conditions when combined with a global electronic map of the considered environment. Passive navigation would be an ideal solution for passengers who are not familiar with interactive applications and for in-flight entertainment (IFE) systems that are not equipped with interactive controls. However, the literature provides inconsistent results on the differences between active and passive navigation in terms of spatial knowledge acquisition and usability.

- Unlike other studies in the literature, we test user performance in a virtual evacuation in clear as well as reduced visibility, thus simulating more realistic emergency conditions.

- Besides quantitative metrics of spatial knowledge, we take into consideration subjective usability metrics such as enjoyment or comprehension that might have a significant impact on the acceptability of a specific tool by the general public. 
Results of our study show that a VE-based approach has the ability to improve the acquisition and application of spatial knowledge by prospective passengers, thus bringing a positive contribution to aviation safety. Both VE conditions produced better spatial knowledge when users were asked to pinpoint their assigned position in the aircraft, and the active navigation condition produced a performance improvement in a subsequent virtual evacuation. Users perceived the active navigation condition to be better than printed maps in terms of comprehension, effectiveness, and attention and better than passive navigation in terms of feedback and sense of control, while both VE conditions were perceived as more enjoyable than printed maps.

The paper is organized as follows. Section 2 surveys the research literature on spatial knowledge acquisition from maps and VEs and on active/passive navigation of VEs, motivating our work from the point of view of VE research and highlighting its relevance to aviation safety. In Section 3, we illustrate in detail the VE-based tool we have developed. In Section 4, we present the experimental method used to evaluate the two versions of the tool and contrast them to the traditional map approach followed by airlines. Section 5 presents the results of the experiment while Section 6 discusses findings and limitations of the study. Section 7 contains conclusions and outlines future work.

\section{Related work and motivations}

In this section, we first survey relevant research on navigation in VEs, examining the differences in spatial knowledge acquired from maps and VEs and motivating the need for investigating passive vs. active navigation. Then, we illustrate why aviation safety is a particularly relevant application domain for this area of research.

\subsection{Spatial knowledge acquisition through maps and VEs}

Maps are one of the most relied-upon tools to acquire spatial knowledge of an unknown environment. In particular, they allow people to quickly obtain survey knowledge (Siegel and White, 1975), making it possible to carry out spatial tasks (e.g., judging relative locations) more accurately and faster compared to learning the environment through direct navigation (Lloyd, 1989; Thorndyke and Hayes-Roth, 1982). However, map learning produces representations of the environment that are orientation-specific: learning an environment from a map makes it difficult to carry out spatial tasks that involve directions that are not aligned with the original orientation of the map (Aretz and Wickens, 1992; Levinew et al., 1984).

Research on the effectiveness of VEs compared to maps for spatial knowledge acquisition obtained mixed results. Witmer et al. (1996) found that the study of a paper map of a complex office building before navigating a VE model of the building or the real-world building had no significant effects on measures of survey knowledge or route knowledge (i.e., knowledge of the sequence of features and/or actions that describe a path between two known points (Siegel and White, 1975)). Bliss et al. (1997) did not find performance differences in a route-following task in a real-world building between firefighters who trained for 15 minutes with a VE model and those who trained with a paper map of the building. Philbin et al. (1998) found instead that people who trained with a paper map of a building outperformed people who trained for the same amount of time (10 minutes) with a VE of the building, both in traveling through the real environment and answering questions about distance between objects in the environment. Ruddle et al. (1997) found that participants who examined a paper map of a large-scale building were significantly more accurate in estimating relative and absolute distances in the real building compared to participants who extensively navigated a VE reconstruction of the building. Similarly, 
Richardson et al. (1999) found that participants who were exposed for 6 minutes to a map or real-world navigation of a complex building were better at learning the environment compared to participants who used a VE of the building for the same amount of time.

These studies seem to suggest that VEs allow people to initially acquire route knowledge of an environment and that only a small or simple VE makes it possible to acquire survey knowledge with relative ease (Richardson et al., 1999; Rossano et al., 1999; Witmer et al., 2002).

A few studies in the literature investigated whether a combination of maps and VEs could be more effective than either condition, obtaining again mixed results. Darken and Banker (1998) did not find significant differences in navigation performance of a natural environment between people who trained with a VE+electronic map condition, those who trained with only a paper map and those who trained with a paper map in the real world, except for people with intermediate spatial ability who benefited more from the VE and map combination. In a related study, Goerger et al. (1998) found that errors in estimation of direction were roughly the same for a group of participants who could train in a VE of a complex multi-floor building as well as consult paper floor maps and a group who had access to the floor maps only. However, the map group made fewer route-following errors and was significantly more accurate in distance-estimation tasks. Diaz and Sims (2003) compared a VE-only, an electronic map-only, and a VE+electronic map condition in a spatial knowledge task in which participants learned the locations of several targets in a simulated building. The electronic map-only condition turned out to be the most accurate for distance estimation while the VE+electronic map condition was better for route learning.

Our study will further the investigation of the possible positive effects of combining electronic maps and VEs compared to paper maps only. By having the ability to access different representations of the considered environment at the same time, one should be able to gain both route and survey knowledge without the need for extensive navigation of the VE. This is an advantage when the time that people are willing to devote to the examination of evacuation instructions is limited, as it is the case of aircraft passengers. Our choice of combining both a $\mathrm{VE}$ and a map representation of the aircraft cabin derives also from constraints of the aviation domain, in which it is mandatory to provide passengers with a diagrammatic representation that gives the location of every available exit in the cabin (U.S. Department of Transportation, 1999). Unlike other studies of spatial knowledge acquisition from maps and VEs, we also take into consideration some usability metrics (e.g., comprehension, enjoyment, etc.) that can be important for the suitability of maps and VEs for the general public.

\subsection{Passive and active navigation in VEs}

Interest in the implications for spatial learning of passive and active navigation of an environment emerged after Appleyard (1970) pointed out that passengers on a bus acquired only route knowledge of a city while bus drivers acquired also survey knowledge. A number of the studies that followed investigated active and passive navigation in VEs. In these studies, active navigation typically involves movement in the VE with no constraints but collision detection, using some form of control device (e.g., mouse, keyboard, joystick). Passive navigation consists instead in observing pre-determined recorded routes through videos, slides or automatic motion in the VE.

In one of the first investigations of active and passive navigation in VEs, Péruch et al. (1995) compared three conditions: an active condition in which participants could freely explore a VE composed of cubes and walls using a joystick, a passive-dynamic condition in which participants watched a video showing an exploration of the VE, and a passive-snapshot condition in which participants viewed slides of the exploration video. Participants were exposed to the conditions 
for 4 minutes. During testing, participants had to take the shortest route to reach four landmarks in the VE. The active condition led to significantly higher performance compared to the passivedynamic condition, which was significantly better than the passive-snapshot condition. Farrell et al. (2003) found that using a keyboard to actively navigate a desktop VE (a model of the first floor of a university building) led to improved navigation in the corresponding real building compared with having no prior experience in the environment. However, passively watching an experimenter navigate the VE did not result in statistically significant improvement (this might have been affected by the low power of the analysis in detecting effects). In Carassa et al. (2002), actively exploring a two-floor virtual building with a joystick led to better wayfinding abilities compared to following an avatar through the building. In both conditions, participants used a head-mounted display (HMD) and were exposed to the VE for about 40 minutes. The results seem to suggest that it is the decisional component of active navigation (i.e., deciding where to move in the VE) that leads to improved spatial knowledge. In a series of studies on the effect of navigation mode on the transfer of spatial knowledge, Wallet et al. $(2008,2013)$ compared an active condition in which participants used a joystick to follow a route in a virtual district with a passive condition in which participants viewed a recording of the route. In both conditions, directions were given by a researcher. Results provided evidence of a beneficial effect of active navigation, especially in egocentric spatial recall tasks.

Unlike the above mentioned studies, the experiment conducted by Wilson et al. (1997a) using a complex yoked design did not reveal any advantage of active over passive navigation of a desktop VE. In the active-with-movement condition, participants could control where to go in the environment using a keyboard, while the passive-without-movement group viewed the corresponding display. In the active-without-movement condition, participants could decide where to go but had to communicate the decision to yoked passive-with-movement participants, who carried out the action with the keyboard. A control group included participants who were not exposed to the VE before carrying out the test phase. In the test phase, participants carried out a pointing task in which they were positioned at one of three landmarks in the VE and had to point to the other two landmarks, and a drawing task in which they drew a map of the VE. While the control group made significantly larger pointing errors compared to the other groups, no differences were found between any of the groups who were exposed to the VE.

To investigate their opposing findings, Wilson and Péruch (2002) conducted a joint study in which active participants navigated a VE while passive participants either watched the active participants move on the same display or viewed a video of the display. Results show that the first group of passive participants was more accurate at pointing to the targets compared to the second group and that they were more accurate than active participants in wayfinding. These results contradict both previous findings of no difference (Wilson et al., 1997a) or better performance by active navigators (Péruch et al., 1995). To resolve these inconsistent findings, Wilson and Péruch (2002) tested both the active and passive conditions in a within-group design, with all yoked pairs sitting side-by-side during exploration. In this case, they found no differences between conditions for any of the dependent measures. Christou and Bülthoff (1999) carried out a related experiment in which they paired active navigators who used a trackball to explore a virtual house with passive observers who watched a recorded sequence of the active navigators movements. They found no difference in scene recognition between the active and passive groups. Similarly to Péruch et al. (1995), Gaunet et al. (2001) compared an active, a passive-dynamic, and a passivesnapshot condition in a route-following task through a VE in a driving simulator. In the active condition, users controlled movement in the VE with a joystick but were verbally instructed by the experimenter about the route to follow. In the passive condition, users watched a video of 
the same VE route, while in the snapshot condition users looked at sample views taken from the video. The authors did not find any difference among conditions in a pointing task (pointing toward the origin of the route from its end position) or in a scene recognition task. The only difference was found in route drawing, in which the snapshot group performed worse in terms of distance and angle errors. Ragan et al. (2012) investigated the effect of navigational control on users' ability to learn facts distributed among various locations within a VE. They compared a passive navigation condition in which learners were taken to pre-recorded navigation points without any user control and an active navigation condition in which learners used a wand device to control movement within the VE. The training phase took a total time of about 10 minutes in both conditions. No significant differences were found in terms of learning outcomes but participants remembered more landmarks with passive navigation.

Due to the large differences in terms of VE complexity, spatial tasks, control devices, and exposure to the environment in the different conditions, drawing definitive conclusions from these studies is difficult. In their review of the literature on active and passive navigation, Chrastil and Warren (2012) claim that the literature offer little support for an effect of active versus passive navigation in VEs and that the inconsistent findings are probably due to differences in experimental design. Other researchers suggest that active navigation is particularly beneficial in egocentric frame situations and when a high level of exocentric knowledge is required due to the VE complexity and/or spatial recall tasks (Wallet et al., 2008, 2013).

The relatively low structural complexity of the VE considered in our study, the general familiarity people have with the abstract shape of an aircraft, and the constraints such shape poses to cabin navigation, would suggest that we should not find differences in the spatial knowledge acquired from an active and a passive navigation condition. Passive navigation would represent an ideal solution to provide safety instructions to aircraft passengers because (i) it would extend the accessibility of the approach also to passengers who are not familiar with interactive applications, and (ii) it would make it possible to present first-person instructions on a larger fleet of aircraft, because not all in-flight entertainment (IFE) systems on current airliners are equipped with interactive controls. However, no study in the literature on active/passive navigation has investigated if there are other measures, besides spatial knowledge metrics, that could differentiate the two conditions, e.g, in terms of usability. Therefore, in addition to comparing active and passive navigation in terms of spatial knowledge acquired, our study will also consider subjective measures that could make users prefer one condition to the other.

\subsection{Aircraft evacuation}

Fast and safe evacuation of aircraft during emergencies is a fundamental aspect of aviation safety. The need for high evacuation efficiency is motivated by the fact that the aircraft cabin becomes an unsurvivable environment in about two minutes when fire erupts (Muir and Thomas, 2004). Unfortunately, the diagrammatic maps provided to passengers by the safety card in the seat pocket do not seem to be particularly effective to prepare them for emergency evacuation. Indeed, most passengers do not pay attention to these materials and for those who do pay attention comprehension has been shown to be below acceptable limits (Corbett et al., 2008). The inadequacy of safety cards is confirmed by passengers who have been involved in real emergencies. For example, in a recent study (Chang and Yang, 2011) of the emergency evacuation experiences of 110 passengers involved in a serious aircraft accident and evacuation, only $16 \%$ of the passengers found the safety cards to be useful with respect to their need of evacuating the burning aircraft. The majority of passengers said that these tools are not sufficient for dealing with emergency evacuation and they did not feel to have been clearly helped by them. 
Using VE-based tools to provide spatial knowledge for emergency evacuation could bring several advantages with respect to traditional printed map solutions. First, accurate and interactive 3D graphics would provide the passenger with a detailed and dynamic visualization of the cabin environment of the specific aircraft type (s)he is flying with. Unlike safety cards, this visual representation would include the whole cabin environment and could be examined from any possible viewpoint to maximize comprehension. Second, instead of illustrating evacuation routes in a generic one-size-fits-all format (as today's safety cards), an interactive tool could consider the specific seat on which the passenger is seated on the aircraft and provide a personalized illustration. For example, each passenger could receive a clear indication of which are the closest exits to him/her, the paths to reach those exits, and his/her alternate exits in case the closest ones are unusable. Third, the passenger could be able to see how the cabin environment changes in possible different emergency conditions, e.g., night evacuation or smoke-filled cabin. Fourth, augmenting first-person, lifelike experiential exploration of the VE and the evacuation routes with a synchronized interactive map of the cabin could help users better understand where they are in the virtual aircraft with respect to the position of relevant objects such as the different exits and the passenger's own seat.

\section{The proposed VE-based tool}

The VE-based tool we developed has been designed to be used on-board the aircraft on IFE systems or as an app on passengers' mobile devices, whose use will be progressively allowed during all phases of flight by the latest FAA and EASA policies. Figure 1 shows the organization of the screen, which is divided in two parts: $80 \%$ of the available space is devoted to show the VE of the aircraft cabin, while the remaining $20 \%$ (on the right) is used to display the electronic map of the aircraft. The map shows the aircraft cabin from above, front-up, and includes a youare-here symbol that highlights the current position and orientation of the user in the VE, as well as exit signs near each door.

The tool offers the passenger a virtual tour of the cabin, specifically aimed at understanding the spatial position of his/her seat as well as the position of every possible exit. The tour starts from the passenger's seat and takes him/her to the front of the aircraft. Then it goes through the following fixed sequence of points of interest: front exits, overwing exits, and rear exits. While moving from the front to the rear, the tour points the attention of the user to his/her seat when she passes by that specific seat. Finally, after reaching the rear exits, the user is led back to his/her seat to conclude the tour. This organization of the tour guarantees that participants can experience the entire cabin VE from the front-to-rear as well as the rear-to-front direction.

The considered sequence of points of interest covers the structure of typical single-aisle, narrow body aircraft such as the Airbus A320 or the Boeing 737, but can be easily changed for other types of aircraft which can have a larger or smaller number of exits.

As shown in Fig. 2, a semi-transparent text panel can appear at the bottom of the VE area. Textual messages are used to provide instructions, to indicate the current destination (in the sequence of points of interest previously listed), and to confirm that the destination has been reached. For example, Fig. 2 shows the message displayed when the front right exit has been reached. The current destination is also highlighted inside the 3D world with a glow effect at the destination that disappears once the destination is reached. Similarly, the map highlights the exit or seat corresponding to the current destination. The use of these effects should contribute to attract passenger's attention on the points of interest (Hughes and Lewis, 2002). 


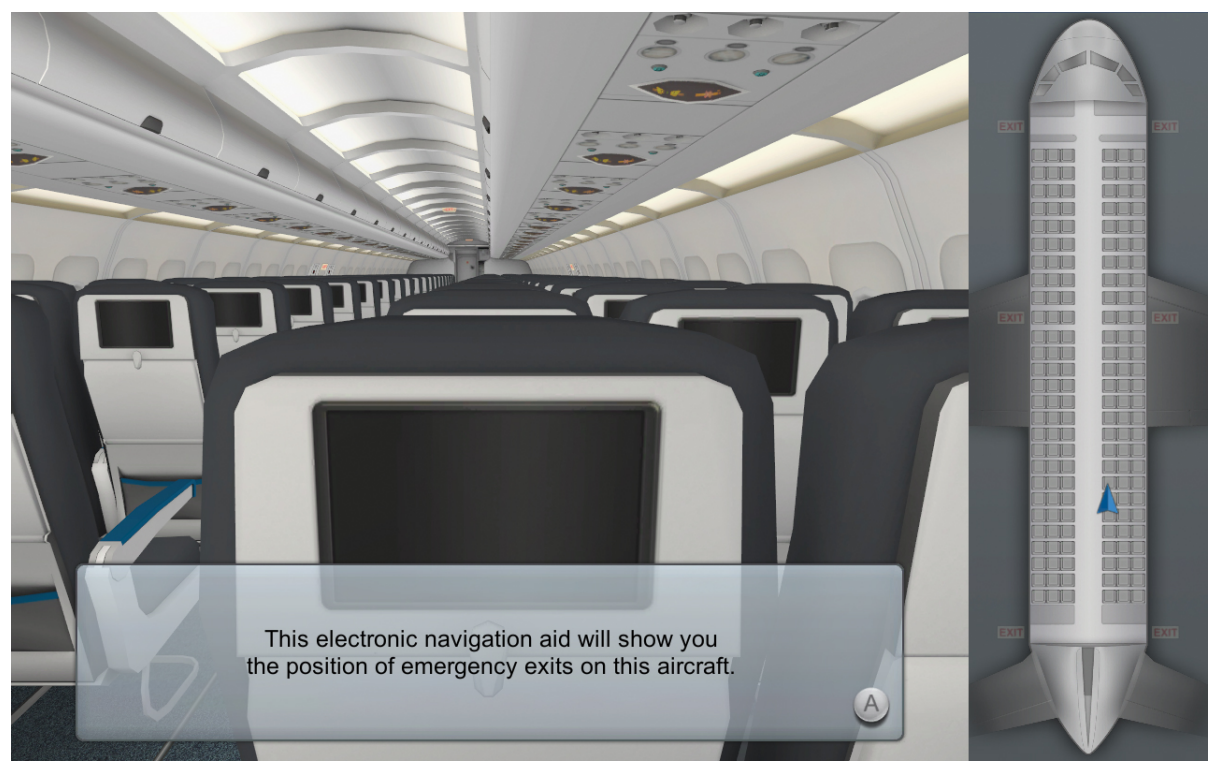

Figure 1: Initial screen in the Active and Passive navigation conditions. Most of the screen shows the VE of the aircraft cabin, a seat map of the aircraft is shown on the right, while a message panel on the bottom conveys instructions.

The tool supports active as well as passive navigation. In Active navigation mode, passengers can control their movement in the VE using different control devices, e.g., a joystick or keyboard keys (the specific controls used in the experiment are described in Section 4.3). In Passive mode, movement in the VE is automatically controlled by the tool and passengers have only to press a single button to advance to the next step in the tour. As in all other studies on active and passive navigation, movement is limited to walking in the VE. While constraining movement does not provide passengers with the opportunity to examine the VE from all possible points of view (e.g., through a flying navigation mode), it simplifies movement control, makes it easier to match the virtual experience with the real world navigation experience, and can offload some of the cognitive effort of navigating 3D environments (Elmqvist et al., 2008).

\section{Method}

To evaluate the effectiveness of the proposed tool in providing spatial knowledge about the location of exits in an aircraft, we carried out a lab study comparing a version of the tool with Active navigation, a version with Passive navigation, and a traditional Safety Card (in the following, the three approaches will be referred to as Active, Passive and Card).

\subsection{Design}

The study involved three phases:

- A boarding phase in which we simulated with an immersive VR setup the process of boarding an Airbus A320 aircraft and reaching the assigned seat on it. This phase was introduced because passengers are exposed by airlines to safety materials after boarding a plane. 


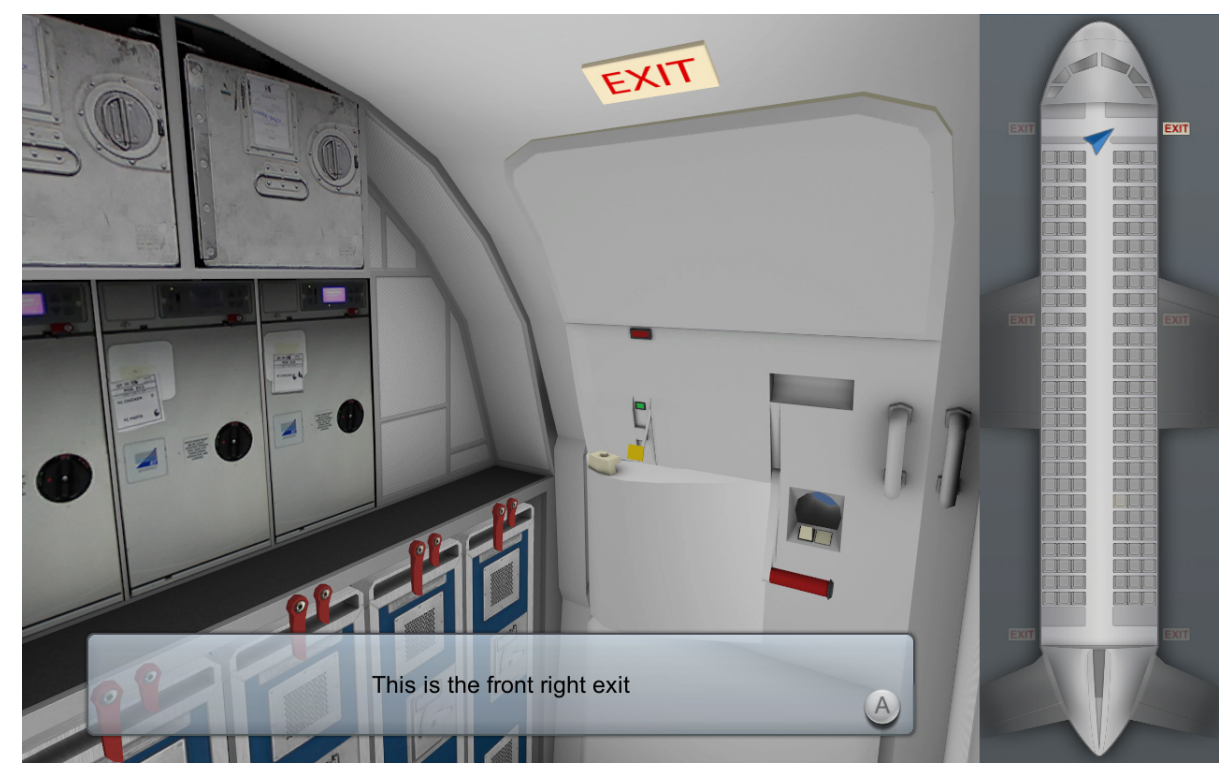

Figure 2: The text in the message panel is informing the user that (s)he is looking at the front right exit.

- A training phase in which participants examined one of the three considered types of safety materials (Active, Passive or Card) to obtain knowledge about the location of emergency exits in the A320 aircraft they boarded. In the Active and Passive conditions, this phase was carried out with a desktop VR setup. In the Card condition, participants were exposed to a paper safety card.

- A knowledge testing phase consisting of: a) spatial tasks on paper aimed at assessing participants' spatial knowledge of the aircraft, b) usability questionnaires to assess participants' subjective experience with the approach they tried, and c) two simulated evacuations from the aircraft using the immersive VR setup to assess the transfer of spatial knowledge to evacuation scenarios under two different visibility conditions. The use of an immersive VR setup reduces the chance of intermodality transfer between training and testing in the Active and Passive conditions, providing no advantage for these conditions compared to the Card condition.

In general, the study followed a between-subjects design, with training approach as independent variable. To take into account the two visibility conditions in the simulated evacuations in the knowledge testing phase, we followed instead a mixed-design model, with training approach as between-subjects variable and visibility condition as within-subjects variable.

In the training phase with Active and Passive conditions, participants saw the same desktop VE reconstruction of the A320 aircraft cabin together with a synchronized 2D electronic map of it (Fig. 1), and were guided from point of interest to point of interest in the virtual tour of the cabin by instructions that appeared in the semi-transparent message panel at the bottom of the screen. In the Card condition, participants were exposed to a paper safety card that showed an abstract representation of the aircraft with emergency exits clearly highlighted through red arrows (Fig. 3). This is representative of the approach currently followed by airlines and mandated by 


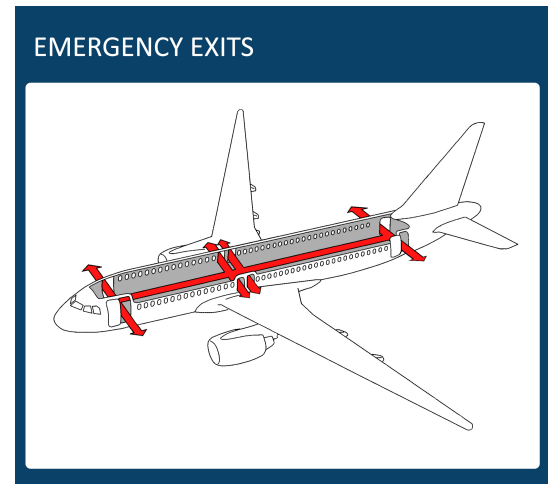

Figure 3: The safety card used in the study. It shows an abstract representation of the considered aircraft with all emergency paths and exits highlighted with red arrows.

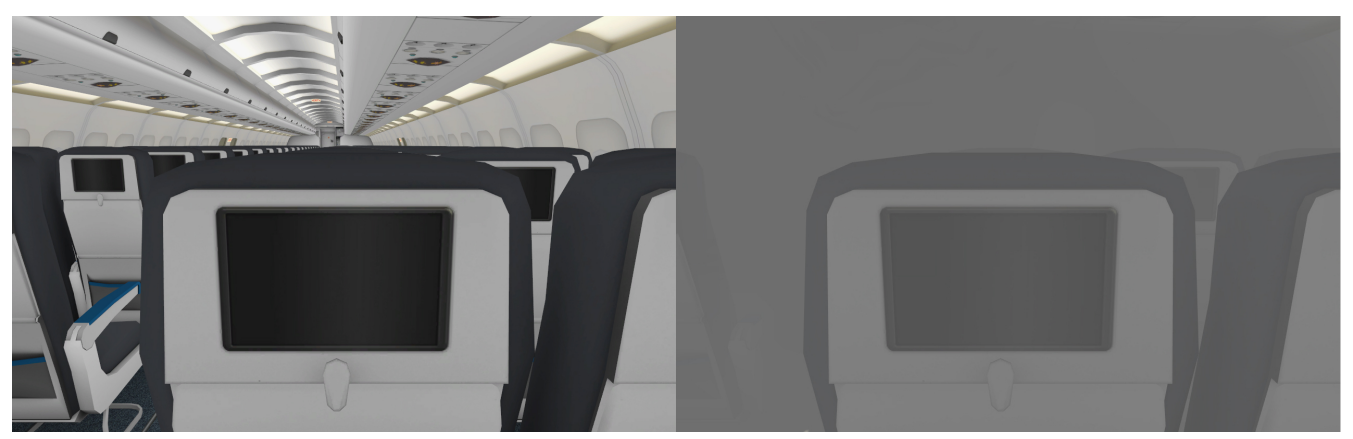

Figure 4: Comparison of the two visibility conditions used in the simulated evacuations (clear view on the left, reduced visibility on the right).

aviation regulations (U.S. Department of Transportation, 1999). The abstract representation we used was taken from actual A320 cards.

In the simulated evacuations of the testing phase, participants used the immersive VR setup to navigate the VE of the Airbus A320 cabin and reach the closest exits, starting from their assigned seat. The two evacuations differed in terms of visibility conditions (Fig. 4): in one, participants had a clear view of the cabin while the other reproduced a "smoke in the cabin"situation that reduced visibility to a short distance from the seat.

\subsection{Participants}

We recruited a total of 54 participants (44 male, 10 female) among undergraduate Computer Science students at our university. Participants received small course credit for their participation. Eighteen participants were assigned to each experimental group using a computer-assisted procedure that minimized differences in mean and variance among the three groups for male/female ratio, age, number of flights in the last two years, flight anxiety, experience with 3D applications/games, experience with game controllers, and spatial ability. Due to hardware problems that occurred during the simulated evacuations with one of the members of the Active group, we had to exclude the corresponding data from the analysis. In the following sections, we will focus on the data from the remaining 53 participants. 
The mean age of participants was $23.34(\mathrm{SD}=4.74)$. Participants were familiar with 3D applications/games and game controllers, were occasional flyers, and had a low level of flight anxiety. More specifically, we assessed such individual characteristics by asking participants to indicate the number of flights they took in the last two years (each flight segment counted as a different flight), and to rate their familiarity with 3D applications/games, familiarity with game controllers, and flight anxiety on a 7-point scale (1=not at all, $7=$ very high). Means in the Active, Passive and Card groups were respectively 3.18 ( $\mathrm{SD}=4.17), 3.28(\mathrm{SD}=6.70), 2.11(\mathrm{SD}=2.95)$ for number of flights; $4.88(\mathrm{SD}=1.69), 4.67(\mathrm{SD}=1.71), 4.72(\mathrm{SD}=1.56)$ for familiarity with $3 \mathrm{D}$ applications/games; $5.18(\mathrm{SD}=1.70), 4.94(\mathrm{SD}=1.70), 4.67(\mathrm{SD}=1.61)$ for familiarity with game controllers; and $2.53(\mathrm{SD}=1.33), 2.78(\mathrm{SD}=1.44), 2.67(\mathrm{SD}=1.75)$ for flight anxiety. The very small differences among the three groups were not statistically significant $(p>0.50$ for all variables) as confirmed by a Kruskal-Wallis test.

We assessed spatial abilities with the Santa Barbara Sense of Direction Scale (SBSOD) (Hegarty et al., 2002). Unlike psychometric spatial ability tests such as the Group Embedded Figures test (Oltman et al., 1971) and the Vandenberg Mental Rotation Test (Vandenberg and Kuse, 1978), the SBSOD is a self-report measure of environmental spatial ability. Participants indicated their level of agreement with each of the 15 statements in the SBSOD on a 7-levels Likert scale ranging from 1 ("strongly agree") to 7 ("strongly disagree"). A higher average score across items indicates better spatial abilities. Mean SBSOD scores in the Active, Passive and Card groups were respectively $4.60(\mathrm{SD}=0.87), 4.34(\mathrm{SD}=1.00), 4.41(\mathrm{SD}=0.85)$, and the differences among the three groups were not statistically significant $(p>0.70$, Kruskal-Wallis test).

\subsection{Materials}

The VE used in the study is a detailed reconstruction of the cabin of an Airbus A320 aircraft, implemented using $\mathrm{C \#}$ and Unity3D. The cabin includes 27 rows of seats, with a $3+3$ layout configuration ( 3 seats on each side of the central aisle), and has 8 exits: 4 overwing exits (1 between rows 9 and 10 and 1 between rows 10 and 11, on each side), 2 front exits and 2 rear exits. Front exits and rear exits are only visible when approaching the galley areas at the front and the back of the cabin. The cabin is highly detailed and includes a reproduction of an IFE system on each backseat and all the emergency-related equipment that is typically visible in real aircraft such as evacuation lights on the floor and exit signs above each door. Overall, the cabin shows a high degree of symmetry, regularity, and continuity, and can be almost entirely perceived from the far ends of the central aisle.

For the boarding phase, we used an extended version of the VE that included the external boarding bridge leading to the front left exit of the aircraft.

Figure 5 shows the equipment used in the training phase. A 30", 2560x1600 pixel LCD monitor showed the aircraft cabin from the point of view of a passenger seated on the right aisle seat of the 19th row. The IFE system display depicted in the front seat contained the VE-based tool in a 1059x662 pixels area, reproducing the size and appearance a real IFE display would have on board the aircraft. The distance between the screen and the user was about $0.4 \mathrm{~m}$. In the Active condition, the directional cross of a Nintendo WiiMote controller was used by participants to control their movement in the VE: the up and down directions on the cross allowed participants to move respectively forward and backward, while the right and left directions were used to rotate respectively right or left. The choice of the WiiMote as control device was motivated by its similarity with real-world IFE control devices in terms of size and directional cross. The A button of the controller was used in the Active as well as Passive condition to move to the next phase of the cabin tour. 


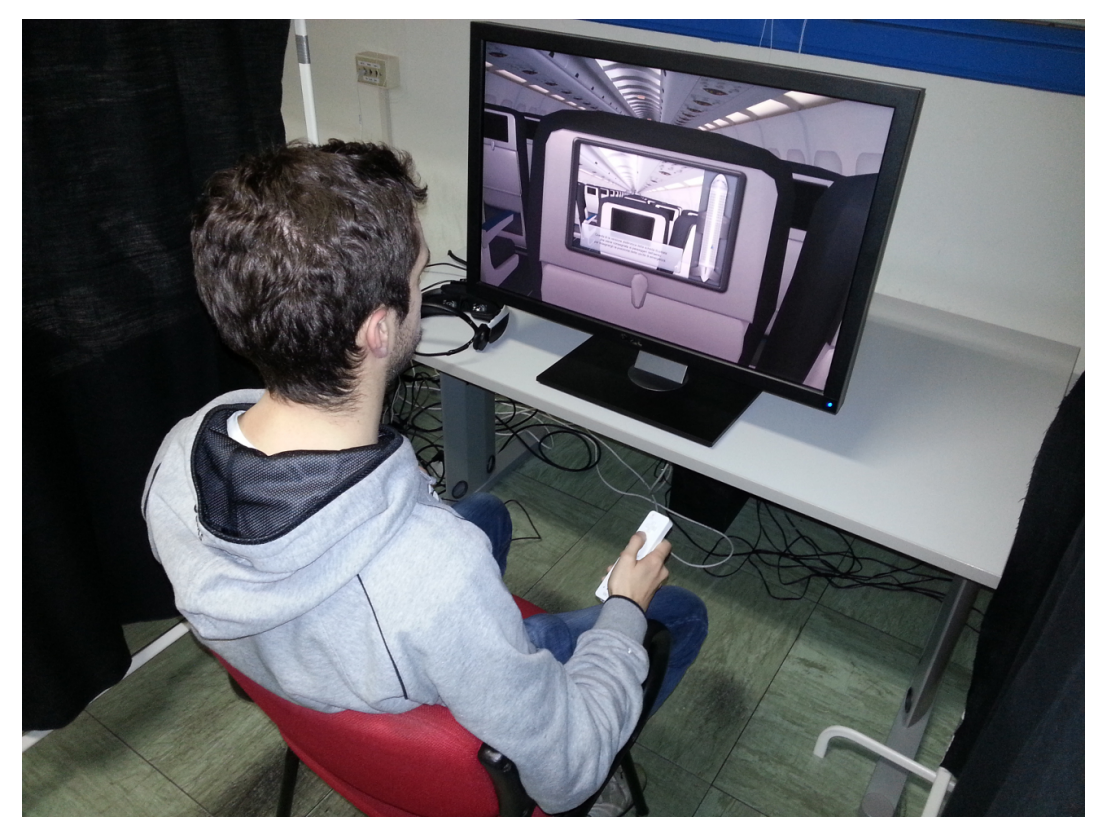

Figure 5: The equipment used in the training phase of the experiment.

Movement speed in the Active and Passive condition was the same $(1 \mathrm{~m} / \mathrm{s})$. This guaranteed that the minimum time participants spent in the VE (considering a participant who immediately advanced to the next step in the tour after having reached a point of interest) was the same in the two conditions (about 83 seconds). We also designed the Active condition in such a way that participants who spent more than 4 seconds without moving were reminded to reach the next point of interest through a message on the bottom panel. If a participant moved in the wrong direction (i.e., opposite the correct one) for more than 5 seconds, the tool was programmed to turn back the participant in the correct direction with an animated transition and notify him/her about the correct direction. This was meant to provide a better control of the level of exposure to the VE in the two VE conditions. During the study, we observed some instances of the first event (users stopping for more than 4 seconds) but no instance of the second event (users going in the opposite direction).

The graphical information on the safety card used in the Card condition covered a $17 \times 15 \mathrm{~cm}$ area on a plasticized A4 paper. In this condition, the LCD monitor showed the same passenger's view as in the Active and Passive conditions but the IFE system was switched off.

Table 1 summarizes the major differences in group treatment in the training phase of the experiment. There were no major differences in group treatment in the boarding and testing phases of the experiment.

Figure 6 shows the equipment used in the testing phase for the evacuation simulations. Participants donned a Sony HMZ-T1 stereoscopic HMD with $1280 \times 720$ resolution, $45^{\circ}$ field of view, 3DOF head tracker (InterSense InertiaCube3), and audio headphones, and held a Nintendo Nunchuck joystick in their dominant hand. The up and down commands on the joystick allowed participants to move respectively forward and backward in the VE, while the right and left commands were used to rotate respectively right or left. 


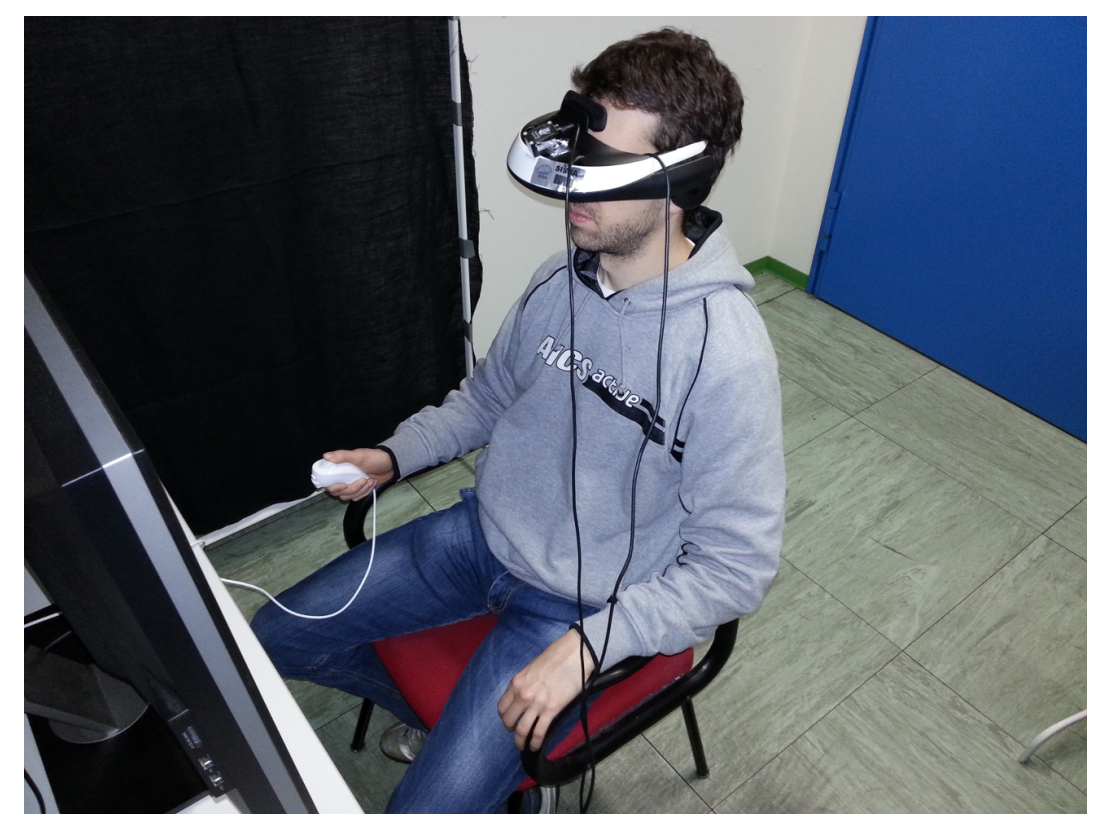

Figure 6: The equipment used in the boarding phase and in the evacuation task of the experiment.

\subsection{Measures}

During the study, we collected data using questionnaires, paper maps and logging code.

\subsubsection{Usability measures}

At the end of the training phase, we administered a questionnaire to obtain users' subjective assessment of the three considered approaches in terms of the following usability measures: enjoyment, attention, effectiveness, usefulness, comprehension, ease of use, feedback, and sense of control. Table 2 shows the list of items included in the questionnaire. Users indicated their level of agreement with each item in the questionnaire on a 7-levels Likert scale ranging from 1 ("strongly disagree") to 7 ("strongly agree"). Scale reliability for enjoyment, usefulness, and comprehension items, measured using Cronbach's alpha, was 0.71, 0.73, and 0.76, respectively. The questionnaire for Card did not include the two questions on feedback and sense of control.

\subsubsection{Workload}

We measured workload using the NASA Task Load Index (TLX) (Hart and Staveland, 1988). NASA-TLX derives an overall score based on the average of ratings on six sub-scales related to mental demand, physical demand, temporal demand, performance, effort, and frustration level. Each sub-scale score can range in the 1-100 interval.

\subsubsection{Spatial knowledge acquisition}

To assess participants' spatial knowledge acquisition, we asked participants to mark the position of their seat and all emergency exits on a paper map of the A320 aircraft (Fig. 7). We measured the spatial error as the distance in terms of number of seat rows between users' marks and correct positions. Errors were then averaged by group (front exits, overwing exits and rear 


\begin{tabular}{ll}
\hline Type of difference & Description \\
\hline Source of spatial & Card: paper safety card \\
information & Active: VE-based tool (cabin tour with active movement control + seat map) \\
& Passive: VE-based tool (cabin tour with automatic movement control + seat map) \\
Information displayed & Card: passenger's view from seat \\
on monitor & Active: passenger's view from seat, VE-based tool on IFE screen \\
& Passive: passenger's view from seat, VE-based tool on IFE screen \\
Messages in VE-based & Card: no messages \\
tool & Active: control instructions, current destination, reminder when no movement for \\
& more than 4 seconds \\
& Passive: control instructions, current destination \\
Control device & Card: no control device \\
& Active: WiiMote (directional cross for movements + A button) \\
& Passive: WiiMote (A button) \\
Exposure time limits & Card: no limits \\
& Active: minimum exposure time of about 83 seconds \\
& Passive: minimum exposure time of about 83 seconds \\
\end{tabular}

Table 1: Major differences in group treatment in the training phase of the experiment.

\begin{tabular}{ll}
\hline Measure & Items \\
\hline Enjoyment & "I liked to use the tool/card" \\
& "While using the tool/card, I temporarily forgot worries about everyday life" \\
& "The tool/card was entertaining" \\
"I could remain concentrated on the tool/card" & "The knowledge provided by the tool/card is easy to apply" \\
Attention & "The knowledge provided by the tool/card is useful" \\
Usefulness & "The tool/card is useful" \\
Comprehension & "I found it easy to understand the information provided by the tool/card" \\
& "The information provided by the tool/card was presented clearly" \\
& "The knowledge provided by the tool/card is easy to understand" \\
& "The knowledge provided by the tool/card is easy to remember" \\
Ease of use & "I found it difficult to use the tool/card" \\
Feedback & "I received confirmation of how well I was performing the task" \\
Sense of control & "I perceived a sense of control on the tool"
\end{tabular}

Table 2: The list of items in the usability questionnaire.

exits). This is motivated by the close proximity of exits of the same group in the cabin of single aisle aircraft.

As an additional measure of spatial knowledge acquisition, we considered the time participants took to reach the closest exits (i.e., the two rear exits) during the two simulated evacuations. We measured both the evacuation time and the waiting time (i.e., the amount of time participants spent without moving in the VE, which is part of the evacuation time) through logging code integrated in the simulation.

Finally, we measured how many times participants did not choose the closest exits during the simulated evacuations.

\subsection{Procedure}

Participants were first invited to take the seat in front of the main monitor. They were then informed that they would try a system showing the emergency exits of an airliner, that they would use a HMD during the test, and that they would fill some questionnaires. No information was given about the specific tasks participants would have to carry out during the test. 


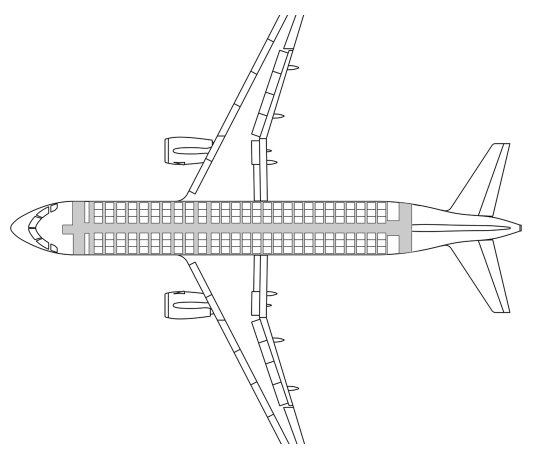

Figure 7: The paper map used to assess participants' spatial knowledge acquisition.

After reading and signing an informed consent form, participants filled the initial demographic and Santa Barbara questionnaires. Based on the data of these questionnaires, the experimenter assigned the participant to one of the three conditions using the above mentioned computer-assisted procedure.

In the subsequent phase, participants donned the HMD and were immersed in the VE to familiarize with controls. The experimenter told participants that they were on the boarding bridge of an aircraft and they had to enter the cabin and reach the seat that was under the only open locker.

Once participants concluded the boarding phase and removed the HMD, they were told that they were seated in the aircraft at the place they had just reached and that they could see the display of the IFE system in front of them. In the Card condition, participants were handed the paper safety card. They were then instructed to carefully look at the card and hand it back to the experimenter when they felt they had understood it. In the Active and Passive conditions, the IFE display showed the start screen depicted in Fig. 1. Participants were instructed to follow the indications provided by the tool through the message panel. Training time in the VE was on average 139.5 seconds in the Active condition, 112.6 seconds in the Passive condition, and 40 seconds in the Card condition.

At the end of the training phase, participants were administered the usability questionnaire, the NASA-TLX, and the paper map for the assessment of spatial knowledge acquisition.

Finally, participants carried out the two simulated evacuations. Before starting the evacuations, participants were informed that they would find themselves seated on the same seat they had reached during the boarding phase and that they had to follow the instructions of an audio message conveyed through the HMD headphones. The message informed participants that they had to immediately evacuate the plane through the closest exits. To counterbalance possible learning effects, half participants in each group carried out the evacuation in the clear visibility condition first, while the other half carried out the evacuation in the reduced visibility condition first.

\subsection{Hypotheses}

Our hypotheses for the study were the following:

1. There would be no performance difference in spatial error in recalling the position of exits and assigned seat, evacuation time, and waiting time between participants who trained in 
the Active condition and those who trained in the Passive condition. This hypothesis is motivated by the lack of evidence of a significant effect of navigation mode in the related literature (Chrastil and Warren, 2012).

2. The Active condition would score higher than the Passive condition in terms of enjoyment, feedback and sense of control because of the higher level of involvement of participants in the VE. Since the two conditions were designed to provide the same information to participants, we did not expect differences in terms of effectiveness, usefulness, and comprehension.

3. Active navigation would require a higher mental workload compared to Passive navigation because of the need to control movement in the VE.

4. Both Active and Passive conditions would allow participants to be more accurate in recalling their initial seat position compared to Card. This was motivated by the fact that our proposed tool makes it possible to personalize the experience based on the passenger's seat while safety cards are generic and do not highlight the passenger's seat.

5. There would be no difference in the spatial knowledge of the position of exits, since all three conditions allow participants to obtain survey knowledge of the aircraft cabin.

6. By combining a source of route knowledge (VE) with a source of survey knowledge (seat map), Active and Passive conditions would make it possible to gain better knowledge of the routes from the passenger's seat to each exit, thus probably benefiting participants in terms of evacuation and waiting time.

7. Both VE conditions would be preferred over Card in terms of enjoyment because of their dynamic and highly visual nature.

8. Both VE conditions would require a higher mental workload compared to the Card condition because of their interactive nature and the need to pay attention to the messages provided by the tool.

9. The lack of points of reference in the reduced visibility condition would increase evacuation time in all conditions due to the higher difficulty in matching the spatial knowledge acquired during training with the VE.

\section{Results}

In this section, we report results of the analysis of the usability measures, workload, and spatial knowledge acquisition.

\subsection{Usability measures}

We used the non-parametric Kruskal-Wallis test to analyze subjective enjoyment, attention, effectiveness, usefulness, comprehension, and ease of use, with training approach as independent variable with three levels (Active, Passive, Card). We used the non-parametric Mann-Whitney test to analyze feedback and sense of control, with training approach as independent variable with two levels (Active, Passive). In case of a statistically significant effect, all Kruskal-Wallis tests were followed by Mann-Whitney post-hoc test with Bonferroni correction. All means are reported in Fig. 8.

For enjoyment, Kruskal-Wallis test revealed a significant effect of training approach $(\mathrm{H}(2)=19, p<0.001)$. Mann-Whitney post-hoc test revealed a statistically significant difference between Active and Card conditions $(\mathrm{U}=34.50, p<0.001, \mathrm{r}=0.66)$ and between Passive 

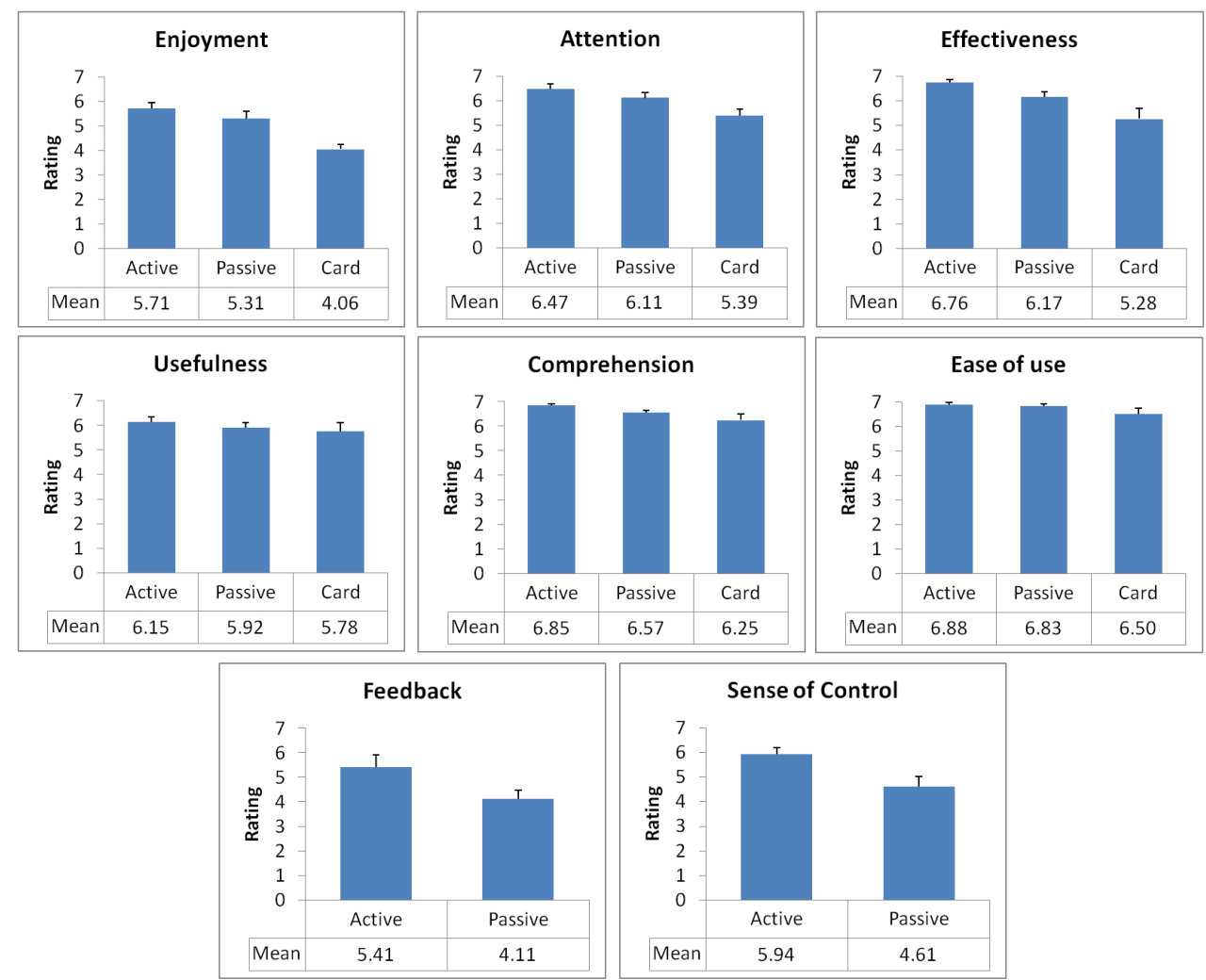

Figure 8: Mean values (with standard error of the mean) of the subjective usability measures (enjoyment, attention, effectiveness, usefulness, comprehension, ease of use, feedback and sense of control) for the three training approaches considered in the study.

and Card conditions $(\mathrm{U}=53.00, p<0.001, \mathrm{r}=0.58)$ with the VE conditions obtaining a higher score in both cases.

For attention, Kruskal-Wallis test revealed a significant effect $(\mathrm{H}(2)=10, p<0.01)$ and MannWhitney post-hoc test revealed a statistically significant difference between Active and Card conditions ( $\mathrm{U}=67.00, p<0.005, \mathrm{r}=0.51)$ with the Active condition obtaining a higher score.

For effectiveness, Kruskal-Wallis test revealed a significant effect $(\mathrm{H}(2)=13.08, p<0.001)$ and Mann-Whitney post-hoc test revealed a statistically significant difference between Active and Card conditions $(\mathrm{U}=56.00, p<0.001, \mathrm{r}=0.59)$ and between Active and Passive conditions $(\mathrm{U}=89.50, p<0.05, \mathrm{r}=0.40)$ with the Active condition obtaining a higher score in both cases.

For usefulness, Kruskal-Wallis test revealed no significant effect $(\mathrm{H}(2)=0.66, p=0.72)$.

For comprehension, Kruskal-Wallis test revealed a significant effect $(\mathrm{H}(2)=8.87, p<0.05)$ and Mann-Whitney post-hoc test revealed a statistically significant difference between Active and Card conditions $(\mathrm{U}=76.50, p<0.01, \mathrm{r}=0.45)$ and between Active and Passive conditions $(\mathrm{U}=81.50, p<0.05, \mathrm{r}=0.42)$ with the Active condition obtaining a higher score in both cases.

For ease of use, Kruskal-Wallis test revealed no significant effect $(\mathrm{H}(2)=1.84, p=0.4)$.

For feedback, Mann-Whitney test revealed a statistically significant difference ( $\mathrm{U}=85.00$, $p<0.05, \mathrm{r}=0.39$ ) between Active and Passive, with Active obtaining a higher score. 

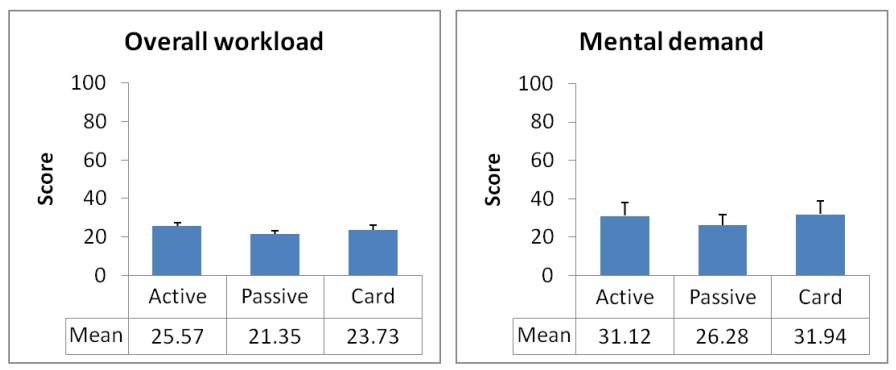

Figure 9: Mean overall workload and mental demand scores (with standard error of the mean) for the three training approaches.

For sense of control, Mann-Whitney test revealed a statistically significant difference ( $\mathrm{U}=82.50, p<0.05, \mathrm{r}=0.41$ ) between Active and Passive, with Active obtaining a higher score.

We also run a Spearman's rank-order correlation to determine the relationship between usability measures and participants' individual characteristics (number of flights, flight anxiety, experience with 3D applications/games, experience with game controllers, and spatial ability). We only found a statistically significant correlation between effectiveness and participants' spatial ability $(\rho(51)=0.348, p<0.05)$ and a statistically significant correlation between effectiveness and participants' number of flights $(\rho(51)=0.277, p<0.05)$.

\subsection{Workload}

The non-parametric Kruskal-Wallis test on the overall NASA-TLX score and the six individual subscale ratings did not reveal significant effects for any of the measures $(\mathrm{H}(2)=3.14$, $p=0.21$ for the overall score). Figure 9 reports means of the overall workload and the mental demand subscale.

We found a statistically significant Spearman's correlation between overall workload and participants' experience with 3D applications/games $(\rho(51)=0.184, p<0.05)$.

\subsection{Spatial knowledge acquisition}

Kruskal-Wallis test on the spatial error in recalling the position of exits and seat (Fig. 10) revealed no significant effect of training approach for front exits $(\mathrm{H}(2)=1.72, p=0.42)$, overwing exits $(\mathrm{H}(2)=1.68, p=0.43)$, and rear exits $(\mathrm{H}(2)=0.78, p=0.68)$. A significant effect was instead found for seat $(\mathrm{H}(2)=14.27, p<0.005)$. The Mann-Whitney post-hoc test highlighted a statistically significant difference between Active and Card $(\mathrm{U}=30.00, p<0.001, \mathrm{r}=0.67)$ as well as between Passive and Card ( $\mathrm{U}=60.50, p<0.01, \mathrm{r}=0.48)$.

To analyze evacuation time and waiting time (means are shown in Fig. 11) we used the nonparametric Aligned Rank Transform (ART) for a mixed-design model (Wobbrock et al., 2011), with training approach as between-subjects variable (levels: Active, Passive, and Card) and visibility condition as within-subjects variable (levels: Clear Visibility and Reduced Visibility). The choice of a non-parametric procedure rather than the more common mixed-design ANOVA was motivated by the lack of homogeneity of variance in the data, as verified with the Levene test. ART on evacuation time revealed a significant main effect for training approach $(\mathrm{F}(2,100)=3.64$, $p<0.05)$, no main effect for visibility $(\mathrm{F}(1,100)=1.07, p=0.3)$, and no interaction effect $(\mathrm{F}(2,100)=0.13, p=0.88)$. Post-hoc contrasts with the adjusted Tukey's HSD method showed 

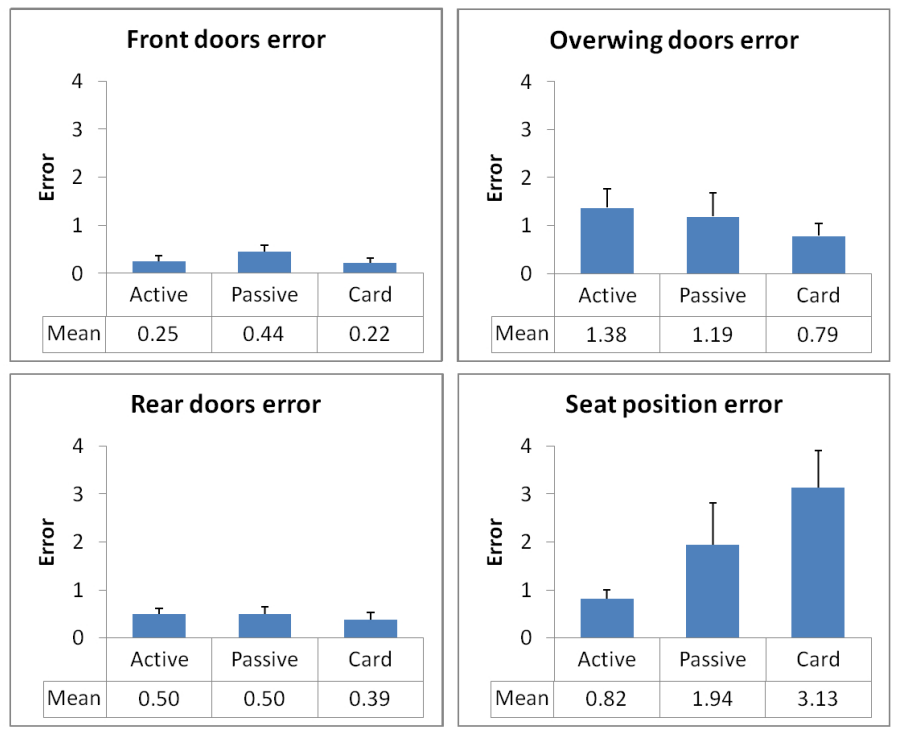

Figure 10: Mean exit and seat position error (with standard error of the mean) for the three training approaches.
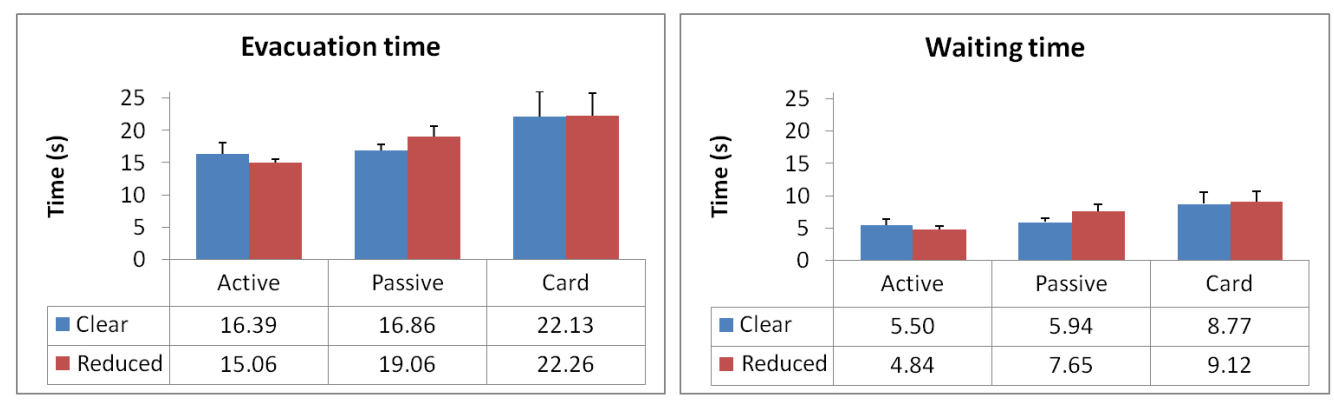

Figure 11: Mean evacuation time and waiting time (with standard error of the mean) for the three training approaches in both clear and reduced visibility conditions.

a statistically significant difference between Active and Card $(p<0.05, \mathrm{r}=0.37)$, with lower times for the Active condition. Similarly, ART on waiting time revealed a significant main effect for training approach $(\mathrm{F}(2,100)=4.42, p<0.05)$, no main effect for visibility $(\mathrm{F}(1,100)=0.92$, $p=0.34)$, and no interaction effect $(\mathrm{F}(2,100)=0.29, p=0.75)$. Post-hoc contrasts with the adjusted Tukey's HSD method showed a statistically significant difference between Active and Card $(p<0.05, \mathrm{r}=0.41)$, and between Active and Passive $(p<0.05, \mathrm{r}=0.24)$, with lower times for the Active condition.

ART was also used to analyze the exit error (Fig. 12) but revealed no main effect for training approach $(\mathrm{F}(2,100)=1.34, p=0.27)$, no main effect for visibility $(\mathrm{F}(1,100)=0.1, p=0.75)$, and no interaction effect $(\mathrm{F}(2,100)=1.76, p=0.18)$.

Finally, no statistically significant correlation was found between any of the spatial knowledge measures (exits and seat position errors, evacuation time, waiting time, exit error) and participants' individual characteristics (number of flights, flight anxiety, experience with 3D ap- 


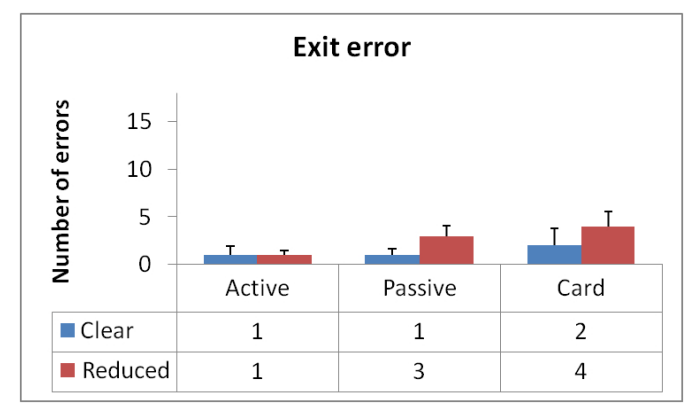

Figure 12: Total number of exit errors for the three training approaches.

plications/games, experience with game controllers, and spatial ability).

\section{Discussion}

Overall, the results point to a positive effect of the VE-based training approach we proposed over the traditional safety card approach, both in terms of spatial knowledge acquisition and subjective usability ratings. However, not all of our expectations were fully supported by the data (Table 3), as we will discuss in the following sections.

\subsection{Active vs. Passive navigation}

In line with hypothesis 1, we did not find significant differences between Active and Passive navigation in terms of the spatial error in recalling the position of exits and assigned seat. This is consistent with other studies in the literature (Christou and Bülthoff, 1999; Gaunet et al., 2001; Péruch and Wilson, 2004; Wilson and Péruch, 2002; Wilson et al., 1997a) and might be explained

\begin{tabular}{|c|c|}
\hline Hypothesis & Result \\
\hline $\begin{array}{l}\text { H1: No statistically significant difference in spatial error, } \\
\text { evacuation time, waiting time between Active and Passive }\end{array}$ & $\begin{array}{l}\text { Partially supported (no significant difference in spatial er- } \\
\text { ror and evacuation time but significant difference in wait- } \\
\text { ing time) }\end{array}$ \\
\hline $\begin{array}{l}\text { H2: Active better than Passive in enjoyment, feedback and } \\
\text { sense of control. No differences in the other usability mea- } \\
\text { sures }\end{array}$ & $\begin{array}{l}\text { Partially supported (significant difference in feedback, } \\
\text { sense of control, effectiveness, and comprehension but no } \\
\text { significant difference in enjoyment) }\end{array}$ \\
\hline $\begin{array}{l}\text { H3: Higher mental workload for Active compared to Pas- } \\
\text { sive }\end{array}$ & Unsupported (no significant difference in workload) \\
\hline $\begin{array}{l}\text { H4: Active and Passive better than Card in seat position } \\
\text { recall }\end{array}$ & Supported \\
\hline $\begin{array}{l}\text { H5: No statistically significant difference among condi- } \\
\text { tions in the spatial knowledge of the position of exits }\end{array}$ & Supported \\
\hline $\begin{array}{l}\text { H6: Lower evacuation and waiting time for Active and } \\
\text { Passive compared to Card }\end{array}$ & $\begin{array}{l}\text { Partially supported (significant difference between Active } \\
\text { and Card) }\end{array}$ \\
\hline H7: Higher preference for Active and Passive over Card & Supported \\
\hline $\begin{array}{l}\text { H8: Higher mental workload for Active and Passive com- } \\
\text { pared to Card }\end{array}$ & Unsupported (no significant difference in workload) \\
\hline $\begin{array}{l}\text { H9: Higher evacuation time for all conditions in reduced } \\
\text { visibility }\end{array}$ & Unsupported (no significant difference in evacuation time) \\
\hline
\end{tabular}

Table 3: Summary of results against the hypotheses. 
by the lack of difference between the two conditions in terms of optic flow, motor, proprioceptive and vestibular body cues. All these factors seem to play a significant role in spatial learning in the real world (Chrastil and Warren, 2012). However, it is possible that the relatively small size of the considered environment and the availability of a map in both conditions might have simplified the acquisition of spatial knowledge, weakening possible differences. Further investigations would thus be needed to clarify this result.

The significant difference we found between Active and Passive navigation in terms of waiting time might be explained by the difference in the level of exposure to the VE during training, as suggested in the literature (Carassa et al., 2002; Farrell et al., 2003; Péruch et al., 1995). A detailed analysis of training times revealed that movement time in the VE (i.e., time spent translating or rotating the view) was almost identical in the two conditions (about 80 seconds). This weakens the probability that optic flow might have played a significant role in causing the observed difference. Optic flow can be used to gain spatial knowledge about distance and angle traveled (Kearns et al., 2002), but it is only available when there is relative motion between an observer and an environment. In addition to moving in the VE, participants took the same time (about 30 seconds) to read messages in the two conditions. This leaves an average of about 30 seconds in the Active condition in which participants were neither moving in the VE nor reading messages. Two types of event seemed to account for most of this time. First, there was a delay between the time participants received an instruction to reach a point of interest and the time they started moving towards that point, probably due to the cognitive process needed to interpret the instruction. No similar delay could be present in the Passive condition because navigation started automatically. Second, sometimes participants stopped short of a point of interest, believing that they had reached it and expecting a confirmation message. When they noticed the error, either autonomously or because a reminder was displayed in the message panel, they restarted moving. It is possible that this greater exposure to the environment during active navigation might have led participants to devote more attention to the spatial layout. However, the literature offers little support for a significant connection between attention and spatial knowledge acquisition (Brooks, 1999; Wilson, 1999; Wilson and Péruch, 2002; Wilson et al., 1997a). Another possible explanation for the difference in waiting time is that the additional time participants spent looking at the VE might have increased their ability to recognize the scene during evacuations. This might have led to faster decisions on the route to follow and consequent improved performance.

Hypothesis 2 was only partially supported. As expected, the higher level of navigation control in the Active condition led participants to perceive higher feedback and sense of control compared to the Passive condition. However, this did not negatively affect the perceived usefulness of the latter condition.

We can only speculate on the motivations for the unexpected differences we obtained in terms of effectiveness and comprehension, and the lack of difference in enjoyment, in part because the literature on active and passive navigation did not take into account such usability metrics. Effectiveness and comprehension were related to the information and knowledge participants could gain through tool use. The Active and Passive versions of the tool were designed to convey the same information. In particular, there were no differences in the sequence of points of interest during the tour, the way in which points of interest were presented and the amount and text of messages (except minor differences in the initial explanation to accommodate the different control mechanism). It is possible that active navigation might entail participants to be more focused and pay more attention to the provided information, even if such increased attention does not result in better spatial knowledge (Chrastil and Warren, 2012; Wilson and Péruch, 2002). Our finding on perceived attention seems to support this hypothesis. 
Our expectation that the Active condition would score higher than the Passive condition in terms of enjoyment results from the evidence that a higher degree of control over navigation in the VE leads to higher sense of presence (Sheridan, 1992; Witmer and Singer, 1998) and that higher presence seems to be associated to greater enjoyment (Sylaiou et al., 2010). It is possible that such an effect did not clearly emerge because the experience in the VE was relatively short and required participants to follow a fixed sequence of points of interest.

Similar considerations could explain the unexpected lack of difference in workload between Active and Passive navigation, which does not provide clear evidence in support of hypothesis 3. While participants had to devote some effort to actively navigate in the VE, they did not perceive such effort to be significantly higher than in the Passive condition. This was probably due to the limited length of the experience and the presence of factors (constrained movement, target highlight) that simplified navigation from a cognitive standpoint. It is also possible that participants' relatively high familiarity with 3D applications and game controllers contributed to decrease the difficulty to control movement in the cabin. However, results of the correlation analysis seem to weaken this hypothesis.

\subsection{VE training vs. Safety card}

In support of hypothesis 4, both Active and Passive navigation allowed participants to obtain better spatial knowledge of their initial seat position compared to the Card condition. This was likely due to the difference in the amount of relevant information about the seat in the three conditions. In particular, the safety card in the Card condition was representative of the safety cards currently used by airlines. These cards are not personalized for the individual passenger due to cost and safety reasons (a procedure would be needed to guarantee that each personalized card is always associated to the correct seat before and during each flight). Participants in the Card condition had only two ways to assess their own initial position: (i) recalling the boarding phase, which simulated boarding the plane and reaching the seat, and (ii) looking at the LCD monitor during the training phase, which simulated the view from the assigned seat. Participants in the VE conditions could additionally exploit knowledge gained through the VE and the electronic seat map.

We could not clearly determine whether knowledge of the seat position in the VE conditions was gained mainly through navigation in the VE, observation of the seat map, or a combination of the two sources. While the seat map should have been the most efficient means to gain survey knowledge (Philbin et al., 1998; Richardson et al., 1999), the relatively small size of the environment could have made it possible to directly gain survey knowledge from the VE (Rossano et al., 1999; Witmer et al., 2002). A brief interview at the end of the study gives credit to this hypothesis, revealing that most participants in the VE conditions focused mainly on the VE and glanced at the map once in a while to get confirmation of their current position.

In line with hypothesis 5 , no differences were found among the three conditions in terms of spatial knowledge of exits. While previous studies found that maps may facilitate some surveyrelated tasks compared to VE+maps conditions (Diaz and Sims, 2003; Goerger et al., 1998), we reckon that the relatively low complexity of our environment might have played a significant role in helping participants recall exit positions. Indeed, the shape of an airplane provides a visual reference frame that gives cues on where exits might be located. Such cues are typically stronger for front and rear exits, which might explain the higher overwing exit error. Unfortunately, we did not measure how much time participants took to carry out the marking task, which might have revealed differences in the mental effort required to extract the spatial knowledge. 
Hypothesis 6 was partially supported. The differences in evacuation time and in waiting time between Active and Card seem to be consistent with other studies in the literature in which a VE+map condition showed advantages over a map-only condition (Darken and Banker, 1998; Diaz and Sims, 2003). In the evacuation task, our participants probably required a combination of survey knowledge to identify the closest exits with respect to their position and route knowledge to move towards the exits. It is possible that participants in the Active condition could better match the survey knowledge they gained with the egocentric experience in the VE, speeding up the decision process during evacuations. Moreover, knowledge acquired by participants in the Card condition was likely orientation-specific (Aretz and Wickens, 1992; Rossano and Warren, 1989), requiring some cognitive effort to be effectively employed during evacuations.

Two other factors related to the experimental procedure might have affected these results. First, we did not control the time participants could spend examining the safety card in the Card condition. On average, such time was lower than the training time in the Active and Passive conditions. However, our choice was motivated by the need to keep the Card condition as similar as possible to the typical reading of a safety card in the real world, without imposing artificial time requirements. Another factor that might have affected the results is the use of the same VE in the training phase and the simulated evacuations. This might have simplified the transfer of knowledge in the Active and Passive conditions. However, there were significant differences between the two phases in terms of output device (desktop monitor vs. HMD), input device (WiiMote vs. Nunchuck), navigation type (guided tour vs. free navigation), and available information (VE+text messages+seat map vs. VE+audio). There was also a practical consideration in defining our procedure: using a VE for the evacuations was the next best thing to using a real or a high-fidelity reconstruction of an A320 aircraft.

As expected in hypothesis 7, Active and Passive conditions were rated higher than the Card condition in terms of enjoyment. This was probably due to the difference between the static nature of the safety card and the dynamic visual nature of the two VE conditions. According to the well-known technology acceptance model (Davis, 1989; Davis et al., 1989, 1992), perceived usefulness, ease of use and enjoyment are the main factors explaining acceptance of an information system. Higher acceptance might lead passengers to higher levels of attention and comprehension of emergency information, which are difficult to obtain with safety cards (Corbett et al., 2008). While we did not find differences between the VE and Card conditions in terms of usefulness and ease of use, participants to our study did indeed perceive that their attention was better engaged with Active navigation and they did also believe that the Active condition was significantly better than the Card in terms of effectiveness and comprehension.

We did not find evidence in support of hypothesis 8 since there were no differences in perceived workload between the two VE conditions and the Card. While navigating the VE required participants to pay attention to multiple sources of information (the cabin itself, the message panel) and required some motor effort in the case of Active navigation, it is possible that the more enjoyable experience and the explicit information conveyed through the message panel contributed to a lower perception of workload.

\subsection{The effect of visibility}

Our expectation that participants would have more difficulty evacuating the aircraft in reduced visibility (hypothesis 9) was not supported by the data. In theory, a clear view of the environment should have sped up the evacuation process because participants should have been able to determine their position in relation to specific points of interest. Despite a lack of studies on the effect of visibility on VE navigation, we expected that the loss of visual cues in reduced 
visibility would have led to degraded situational awareness (Endsley, 1995). In turn, this should have negatively affected decision making and navigation performance.

One possible explanation for our result is that the evacuation task was too easy, requiring only limited spatial knowledge of the environment. However, in such case we would not expect significant differences among the conditions with respect to evacuation times.

A second possible explanation is that the cues that were still available in the environment in reduced visibility (e.g., the position of nearby seats) gave sufficient spatial reference to allow participants to efficiently use their spatial knowledge.

It is interesting to note that those participants who tried to evacuate through the overwing exits in the reduced visibility condition had great difficulty because such exits were easily missed while walking along the central aisle. This observation suggests that visibility has indeed a negative effect on navigation when it hides essential visual clues.

\section{Conclusion and future work}

In this paper, we started investigating how VEs could be employed to prepare people for evacuations. We proposed the design of a VE-based tool for evacuation preparedness and applied it to a real-world domain, aviation safety, in which fast and efficient evacuation is fundamental to increase passengers' chances of survival in case of emergency (Muir and Thomas, 2004). With a user study, we showed that the proposed approach is more effective than the currently employed solution, i.e., the printed diagrammatic maps provided to passengers by airlines, both in terms of spatial knowledge acquisition and subjective measures. We also found that making people experience a tour of the cabin in a mostly passive fashion seems to provide less advantages compared to letting them directly control movement in the VE.

Our study focused on one of the most widely used aircraft currently in operation and we would expect similar findings for other single aisle aircraft like the widely used Boeing 737 series. However, further studies would be needed to investigate whether the promising results we obtained could be generalized to environments that differ considerably in terms of complexity. For much larger and complex areas, such as hospitals, university buildings, or cruise ships, the approach could require adaptations such as the introduction of a dynamic local map along the fixed global map, a combination that has been found to provide benefits in terms of navigation efficiency (Ruddle et al., 1999).

We plan to continue the exploration of the effects of the considered approaches with respect to different VEs, such as twin-aisle, wide-body aircraft, and multi-floor public buildings. We will also study the effect of additional variables that might affect spatial knowledge acquisition through a VE-based approach, such as the availability of a virtual human guiding people in the tour. By investigating multiple variables and environments, we hope to gain a more comprehensive knowledge on how to design effective tools for emergency evacuation preparedness under different conditions.

\section{Acknowledgments}

Our research is supported by a grant of the Federal Aviation Administration (FAA).

We are grateful to Cynthia L. Corbett (FAA Civil Aerospace Medical Institute) and Mac McLean for their precious feedback and encouragement.

Fabio Buttussi and Nicola Zangrando (HCI Lab, University of Udine) significantly helped in the development and evaluation of the VE-based tool. 


\section{References}

Appleyard, D., 1970. Styles and methods of structuring a city. Environment and behavior 2, 100-118

Aretz, A. J., Wickens, C. D., 1992. The mental rotation of map displays. Human Performance 5 (4), 303-328

Arthur, E., Hancock, P., Chrysler, S., 1997. The perception of spatial layout in real and virtual worlds. Ergonomics 40 (1), 69-77.

Bliss, J. P., Tidwell, P. D., Guest, M. A., 1997. The effectiveness of virtual reality for administering spatial navigation training to firefighters. Presence 6 (1), 73-86.

Brooks, B. M., 1999. The specificity of memory enhancement during interaction with a virtual environment. Memory $7(1), 65-78$

Carassa, A., Geminiani, G., Morganti, F., Varotto, D., 2002. Route and survey descriptions of paths: The effect of experience of a large-scale environment. Bulletin of People-Environment Studies, Special Issue on Spatial Cognition 20, 15-17.

Chang, Y.-H., Yang, H.-H., 2011. Cabin safety and emergency evacuation: Passenger experience of flight ci-120 accident. Accident Analysis \& Prevention 43 (3), 1049-1055.

Chittaro, L., Buttussi, F., 2015. Assessing knowledge retention of an immersive serious game vs. a traditional education method in aviation safety. Visualization and Computer Graphics, IEEE Transactions on 21 (4), 529-538.

Chrastil, E. R., Warren, W. H., 2012. Active and passive contributions to spatial learning. Psychonomic bulletin \& review $19(1), 1-23$.

Christou, C. G., Bülthoff, H. H., 1999. View dependence in scene recognition after active learning. Memory \& Cognition 27 (6), 996-1007.

Corbett, C. L., McLean, G. A., Cosper, D. K., 2008. Effective presentation media for passenger safety i: Comprehension of briefing card pictorials and pictograms. Tech. rep., DTIC Document.

Darken, R. P., Banker, W. P., 1998. Navigating in natural environments: A virtual environment training transfer study. In: Proc. Virtual Reality Annual International Symposium. IEEE Computer Society Press, pp. 12-19.

Davis, F. D., 1989. Perceived usefulness, perceived ease of use, and user acceptance of information technology. MIS quarterly 13 (3), 319-340.

Davis, F. D., Bagozzi, R. P., Warshaw, P. R., 1989. User acceptance of computer technology: a comparison of two theoretical models. Management science 35 (8), 982-1003.

Davis, F. D., Bagozzi, R. P., Warshaw, P. R., 1992. Extrinsic and intrinsic motivation to use computers in the workplace1 Journal of applied social psychology 22 (14), 1111-1132.

Diaz, D. D., Sims, V. K., 2003. Augmenting virtual environments: The influence of spatial ability on learning from integrated displays. High Ability Studies 14 (2), 191-212.

Elmqvist, N., Tudoreanu, M. E., Tsigas, P., 2008. Evaluating motion constraints for $3 \mathrm{~d}$ wayfinding in immersive and desktop virtual environments. In: Proceedings of the SIGCHI Conference on Human Factors in Computing Systems. ACM, pp. 1769-1778.

Endsley, M. R., 1995. Toward a theory of situation awareness in dynamic systems. Human Factors: The Journal of the Human Factors and Ergonomics Society 37 (1), 32-64.

Farrell, M. J., Arnold, P., Pettifer, S., Adams, J., Graham, T., MacManamon, M., 2003. Transfer of route learning from virtual to real environments. Journal of Experimental Psychology: Applied 9 (4), 219.

Foreman, N., Stirk, J., Pohl, J., Mandelkow, L., Lehnung, M., Herzog, A., Leplow, B., 2000. Spatial information transfer from virtual to real versions of the kiel locomotor maze. Behavioural Brain Research 112 (1), 53-61.

Gaunet, F., Vidal, M., Kemeny, A., Berthoz, A., 2001. Active, passive and snapshot exploration in a virtual environment: influence on scene memory, reorientation and path memory. Cognitive Brain Research 11 (3), 409-420.

Goerger, S., Darken, R. P., Boyd, M., Gagnon, T., Liles, S., Sullivan, J., Lawson, J., 1998. Spatial knowledge acquisition from maps and virtual environments in complex architectural spaces. In: Proc. 16th Applied Behavioral Sciences Symposium. Vol. 2223. pp. 6-10.

Hart, S. G., Staveland, L. E., 1988. Development of nasa-tlx (task load index): Results of empirical and theoretical research. Advances in psychology 52, 139-183.

Hegarty, M., Richardson, A. E., Montello, D. R., Lovelace, K., Subbiah, I., 2002. Development of a self-report measure of environmental spatial ability. Intelligence 30 (5), 425-447.

Hughes, S., Lewis, M., 2002. Attentive interaction techniques for searching virtual environments. In: Proc. Human Factors and Ergonomics Society Annual Meeting. Vol. 46. SAGE Publications, pp. 2159-2163.

Kearns, M. J., Warren, W. H., Duchon, A. P., Tarr, M. J., 2002. Path integration from optic flow and body senses in a homing task. Perception 31 (3), 349.

Klatzky, R. L., Loomis, J. M., Beall, A. C., Chance, S. S., Golledge, R. G., 1998. Spatial updating of self-position and orientation during real, imagined, and virtual locomotion. Psychological science 9 (4), 293-298.

Levinew, M., Marchon, I., Hanley, G., 1984. The placement and misplacement of you-are-here maps. Environment and Behavior 16 (2), 139-157. 
Lloyd, R., 1989. Cognitive maps: Encoding and decoding information. Annals of the Association of American Geographers 79 (1), 101-124.

Muir, H., Thomas, L., 2004. Passenger education: past and future. In: Proc. 4th Triennial International Aircraft Fire and Cabin Safety Research Conference.

Oltman, P. K., Raskin, E., Witkin, H. A., Press, C. P., 1971. Group embedded figures test. Consulting Psychologists Press Palo Alto, CA.

Péruch, P., Vercher, J.-L., Gauthier, G. M., 1995. Acquisition of spatial knowledge through visual exploration of simulated environments. Ecological Psychology 7 (1), 1-20.

Péruch, P., Wilson, P. N., 2004. Active versus passive learning and testing in a complex outside built environment. Cognitive Processing 5 (4), 218-227.

Philbin, D. A., Ribarsky, W., Walker, N., Hubbard, C. E., 1998. Training in virtual environments: Analysis of task appropriateness. In: Proc. Virtual Reality Annual International Symposium. VRAIS '98. IEEE Computer Society Press, pp. 210

Ragan, E. D., Huber, K. J., Laha, B., Bowman, D. A., 2012. The effects of navigational control and environmental detail on learning in $3 \mathrm{~d}$ virtual environments. In: Proc. IEEE Virtual Reality Conference (Short Papers and Posters). IEEE Computer Society Press, pp. 11-14.

Richardson, A. E., Montello, D. R., Hegarty, M., 1999. Spatial knowledge acquisition from maps and from navigation in real and virtual environments. Memory \& cognition 27 (4), 741-750.

Rossano, M. J., Warren, D. H., 1989. Misaligned maps lead to predictable errors. Perception 18 (2), 215-229.

Rossano, M. J., West, S. O., Robertson, T. J., Wayne, M. C., Chase, R. B., 1999. The acquisition of route and survey knowledge from computer models. Journal of Environmental Psychology 19 (2), 101-115.

Ruddle, R. A., Payne, S. J., Jones, D. M., 1997. Navigating buildings in desktop virtual environments: Experimenta investigations using extended navigational experience. Journal of Experimental Psychology: Applied 3 (2), 143-159.

Ruddle, R. A., Payne, S. J., Jones, D. M., 1999. The effects of maps on navigation and search strategies in very-large-scale virtual environments. Journal of Experimental Psychology: Applied 5 (1), 54-75

Sheridan, T. B., 1992. Musings on telepresence and virtual presence. Presence: Teleoperators and virtual environments 1 (1), 120-126

Siegel, A. W., White, S. H., 1975. The development of spatial representations of large-scale environments. Advances in child development and behavior 10, 9 .

Sylaiou, S., Mania, K., Karoulis, A., White, M., 2010. Exploring the relationship between presence and enjoyment in a virtual museum. International journal of human-computer studies 68 (5), 243-253.

Thorndyke, P. W., Hayes-Roth, B., 1982. Differences in spatial knowledge acquired from maps and navigation. Cognitive psychology 14 (4), 560-589.

U.S. Department of Transportation, Federal Aviation Administration, 1999. Advisory Circular AC 121-24B.

Vandenberg, S. G., Kuse, A. R., 1978. Mental rotations, a group test of three-dimensional spatial visualization. Perceptual and motor skills 47 (2), 599-604.

Waller, D., Hunt, E., Knapp, D., 1998. The transfer of spatial knowledge in virtual environment training. Presence 7 (2), 129-143.

Wallet, G., Sauzéon, H., Larrue, F., N'Kaoua, B., 2013. Virtual/real transfer in a large-scale environment: impact of active navigation as a function of the viewpoint displacement effect and recall tasks. Advances in Human-Computer Interaction 2013,8

Wallet, G., Sauzéon, H., Rodrigues, J., N'Kaoua, B., 2008. Use of virtual reality for spatial knowledge transfer: Effects of passive/active exploration mode in simple and complex routes for three different recall tasks. In: Proc. ACM Symposium on Virtual Reality SoÅtware and Technology. ACM Press, pp. 175-178.

Wilson, P. N., 1999. Active exploration of a virtual environment does not promote orientation or memory for objects. Environment and Behavior 31 (6), 752-763.

Wilson, P. N., Foreman, N., Gillett, R., Stanton, D., 1997a. Active versus passive processing of spatial information in a computer-simulated environment. Ecological Psychology 9 (3), 207-222.

Wilson, P. N., Foreman, N., Tlauka, M., 1997b. Transfer of spatial information from a virtual to a real environment Human Factors: The Journal of the Human Factors and Ergonomics Society 39 (4), 526-531.

Wilson, P. N., Péruch, P., 2002. The influence of interactivity and attention on spatial learning in a desktop virtual environment. Current Psychology of Cognition 21 (6), 601-633.

Witmer, B., Sadowski, W., Finkelstein, N., 2002. Ve-based training strategies for acquiring survey knowledge. Presence $11(1), 1-18$

Witmer, B. G., Bailey, J. H., Knerr, B. W., Parsons, K. C., 1996. Virtual spaces and real world places: transfer of route knowledge. International Journal of Human-Computer Studies 45 (4), 413-428.

Witmer, B. G., Singer, M. J., 1998. Measuring presence in virtual environments: A presence questionnaire. Presence: Teleoperators and virtual environments 7 (3), 225-240.

Wobbrock, J. O., Findlater, L., Gergle, D., Higgins, J. J., 2011. The aligned rank transform for nonparametric factorial 
analyses using only anova procedures. In: Proceedings of the SIGCHI Conference on Human Factors in Computing Systems. ACM, pp. 143-146. 